provides information sufficient to carry out further simple, but useful, and instructive calculations.

Chapters 7 and 8 are extremely valuable as they give a very clear description of the processes taking place in a reactor during start up, normal operation, shut down and power changes during normal operation. The effects of fission product poisons, temperature changes and changes in the content of the fuel are discussod and illustrated by a number of figures. The last chapter is on reactor kinetics and starts by considering the rato of change in the total number of neutrons assuming they are all prompt. This is then followed by a very good description of the effects of delayed neutrons, assuming, to simplify the mathematics, that there is only one group.

There are a few small transcription errors, which fortunately are fairly obvious, otherwise the printing and production are good and the prico is reasonablo. The book can bo thoroughly recommended to both students and professionals interested in the subject.

K. J. DURRANDS

\section{TOWARDS TAILOR-MADE POLYMER MOLECULES}

Block and Graft Copolymers

By Dr. E.J. Ceresa. Pp. xvi $+196+4$ plates. (London: Butterworth and Co. (Publishers), Ltd., 1962.) 42s.

TUMEROUS methods have been used to prepare Dlock and graft copolymers. The author has reviewed these in separate chapters (2-7 inclusive) according to the processes used, that is, transfer and addition, chemical, radical and irradiation, mechanicochemical, condensation and ionic. These syntheses follow an introductory chapter outlining a clear and satisfactory nomenclature for describing tho numerous products which can be classified as block and graft copolymers. Chapters 9 and 10, on the characterization and properties of such copolymers, reveal the chief difficulty in this field, that of obtaining a block or graft copolymer free from homopolymer. As the author points out, only about 20 out of more than 2,000 block and graft copolymers synthesized or claimed have been fully characterized.

Information on this topic is widely scattered. Dr. Ceresa has collected it together in one volume and. has classified it very thoroughly. The copolymer index at the end of the book is a most useful reference table, including roughly 900 of the block and graft copolymers so far synthesized; it is woll crossreferenced to papers dealing with every copolymer listed. The index is, of course, a guide to claims, rather than to completely characterized products.

This book is a review of the literature and the author makes no other claim for it. I feel that it could have been shortened quite appreciably without losing its admirable thoroughness. Thus, the chapters on the preparation of copolymers contain numerous abstracts of experimontal procedures, with references to the original papers. As many of these are examples of the same class of synthesis, it is difficult to see what purpose is served by repetition. Similarly, Chapter 8 (24 pages), dealing with industrial systheses, contains a list of published patent applications with an indication of the method used and the products claimed in each case. Most of these products are listed in the copolymer index and an extension of the references given in the index would have absorbed Chapter 8 .

To expect a critical survey of this field is to be optimistic in view of the limited data available.
Further progress should lead to interesting results relating the structure of macromolecules and their physical properties and will extend, still further, the contributions of polymer chemistry to our knowledge of free radicals and their reactions.

In writing this very thorough roview of the literature, Dr. Ceresa has performed a service to those already familiar with the principles of polymer chemistry and who are interested in block and graft copolymers. The book is well produced and is romarkably free from printing errors-only four were noticed.

S. SMrTH

\section{PALAOBOTANY OF PTERUCHUS}

Bulletin of the British Museum (Natural History) Goology. Vol. 6, No. 2: On Pteruchus, a Microsporophyll of the Corystospermaceae. By John A. Townrow. Pp. 287-320+plates 24-26. (London: British Museum (Natural History), 1962.) 20s.

IICROSPOROPHYLLS called Pteruchus doseribed thirty years ago by the late Dr. Hamshaw Thomas and attributed to Dicroidium, are by far the commonest leaf in the Jriassic of the southerm hemisphero. He placed the whole group of orgars, loaf, microsporophyll and fruits, in the Corystospermaceae and included them in the Pteridosperms. The present publication is the first thorough-going revision of these microsporophylls published since then.

We may begin by noting with pleasuro that Townrow describes no new species, but instead reduces some twenty ill-characterized ones to three. He strongly supports Thomas's attribution of P'teruchus to Dicroidium and its close relatives, and tentatively attributes his three species to particular leaves. His main contribution is, howover, morphological and consists in restricting too wide possibilities. Thomas regarded Pteruchus as a microsporophyll, that is a fertile leaf, and at the same time as an inflorescence, a kind of catkin bearing little bracts and fortile appendages. This idea he put forward deliberately as involving no conflict but instead a triumphant illustration of his "Now Morphology". This "Now Morphology" is an extremely plastic treatment of the categories of 'loaf' and 'stem' which are considered not as fundamentally different but as alternative specializations of tho Rhynia-like shoot system. He went so far as to suggest that the poplar male catkin might have originated in such a form as Pteruchus and that Pteruchus itself was also to be compared closely with the leaf-like microsporophylls of Carboniferous Pteridosperms. It is only fair to add that he did not elaim fully satisfactory knowlodge of Pteruchus and he allowed the possibility that it might be purely a microsporophyll or purely an inflorescence.

Townrow eliminates most of this; Pteruchus he finds is ontirely leaf-like in its origin on the stem and in the fine dotails of its branching. Its symmetry is purely dorsiventral. Any little photosynthetic outgrowths it bears are just small pinnules, borne in exactly the manner of pinnules and not like bracts. It has no inflorescence-like feature at all. This makes it fit comfortably into the Pteridosperm idea as that existed before the "Now Morphology". However, within the Pteridosperms it stands by itself, and Townrow concludes that each of the 'Mesozoic Pteridosperms' seems remote from all the others. We may hope soon to see a work from Townrow revising the seed-bearing organs of these strange plants.
T. M. HARris 